ISSN : $2302-1590$

E-ISSN: $2460-190 \mathrm{X}$

ECONOMICA

Journal of Economic and Economic Education Vol.2 No.2 (134 - 143)

\title{
PENGARUH GAYA KEPEMIMPINAN DAN MOTIVASI KERJA TERHADAP KINERJA KARYAWAN BADAN PUSAT STATISTIK (BPS) KOTA PADANG
}

\author{
Andri Saputra \\ Mahasiswa Program Studi Pendidikan Ekonomi STKIP- PGRI Sumbar \\ Jl. Gunung Pangilun No.1, Padang Sumatera Barat \\ Email: andri.saputra23@yahoo.com \\ Rizky Natassia \\ Dosen Program Studi Pendidikan Ekonomi STKIP- PGRI Sumbar \\ Jl. Gunung Pangilun No.1, Padang Sumatera Barat \\ Email: natassia.rizky@yahoo.com
}

Submited: 2014.03.09 Reviewed: 2014.03.19 Accepted: 2014.04.12

http://dx.doi.org/10.22202/economica.2014.v2.i2.226

\begin{abstract}
This study aims to reveal the influence Effects of Leadership Styles and Work Motivation on Employee Performances Statistics Agency (BPS) of Padang. Type of research is descriptive research Associative. Data were collected through a questionnaire using a Likert scale measuring devices that have been tested errors and reliability in the Central Bureau of Statistics (BPS) of West Sumatra Province. The data analysis technique used is the Path Analysis (Path Analysis).The results of this study are: there is a positive and significant effect between leadership styles on employee motivation Central Statistics Agency (BPS ) Padang, there is a positive and significant effect between leadership styles on employee performance Central Statistics Agency (BPS) Padang, there positive and significant influence between work motivation on employee performance Central Statistics Agency (BPS ) Padang, there is a positive and significant effect between leadership style and work motivation on employee performance Central Statistics Agency ( BPS ) of Padang . Total direct and indirect effects of leadership style variable and employee motivation is at $36 \%$ while the remaining $64 \%$ is influenced by other variables.From the analysis of the data in this study, the authors suggested that the leadership of the Central Statistics Agency (BPS ) Padang further enhance and apply leadership style in order to better motivate employees who are owned by the Central Statistics Agency ( BPS ) Padang be increased as well .
\end{abstract}

\begin{abstract}
Abstrak
Penelitian ini bertujuan untuk mengungkapkanPengaruh Gaya Kepemimpinan Dan Motivasi Kerja Terhadap Kinerja Karyawan Badan Pusat Statistik (Bps) Kota Padang Data dikumpulkan melalui kuisioner dengan menggunakan alat ukur skala likert yang telah diuji kesalahan dan kehandalannya di Badan Pusat Statistik (BPS) Provinsi Sumatera Barat. Teknik analisis data yang digunakan adalah Analisis Jalur (Path Analisis).Hasil dari penelitian ini adalah: terdapat Pengaruh yang positif dan signifikan antara gaya kepemimpinan terhadap motivasi kerja karyawan Badan Pusat Statistik (BPS) Kota Padang, terdapat Pengaruh yang positif dan signifikan antara gaya kepemimpinan terhadap kinerja karyawan Badan Pusat Statistik (BPS) Kota Padang, terdapat Pengaruh yang positif dan signifikan antara motivasi kerja terhadap kinerja karyawan Badan Pusat Statistik (BPS) Kota Padang, terdapat Pengaruh yang positif dan signifikan antara gaya kepemimpinan dan motivasi kerja terhadap kinerja karyawan Badan Pusat Statistik (BPS) Kota Padang. Total pengaruh langsung dan tidak langsung variabel gaya kepemimpinan da motivasi kerja karyawan adalah sebesar $36 \%$ sedangkan sisanya sebesar 64\% dipengaruhi oleh variabel lain.Dari hasil analisis data pada penelitian ini maka penulis menyarankan agar pimpinan Badan Pusat Statistik (BPS) Kota Padang lebih meningkatkan dan menerapkan gaya kepemimpinannya dengan lebih baik lagi agar motivasi yang dimiliki oleh karyawan Badan Pusat Statistik (BPS) Kota Padang lebih meningkat pula.
\end{abstract}

Keywords: Leadership Style, Work Motivation, Performance

C2014 Prodi Pendidikan Ekonomi STKIP PGRI, Padang 


\section{PENDAHULUAN}

Keberhasilan suatu organisasi sangat dipengaruhi oleh kinerja karyawannya. Setiap organisasi maupun perusahaan akan selalu berusaha untuk meningkatkan kinerja karyawannya, dengan harapan apa yang menjadi tujuan organisasi akan tercapai. Berbagai usaha yang dilakukan oleh organisasi dalam meningkatkan kinerja karyawannya, misalnya melalui pendidikan, pelatihan, kompensasi, motivasi, dan gaya kepemimpinan.

Seorang pemimpin adalah orang yang memiliki posisi tertentu dalam hierarki organisasi. Ia harus dapat membuat perencanaan, pengorgnisasian, dan pengawasan serta keputusan yang efektif. Kepemimpinan selalu melibatkan orang lain, oleh karenanya dapat dikatakan bahwa dimana ada pemimpin maka disana ada pengikut yang harus dapat mempengaruhi karyawannya untuk mencapai tujuan organisasi (Anoraga, 2004:183).

Pemimpin mempengaruhi individu maupun kelompok melalui proses komunikasi. Disamping mempengaruhi orang lain untuk bekerja, pemimpin juga harus mendukung kebutuhan-kebutuhan karyawannya demi tercapainya kinerja yang maksimal. Maka, perlu upaya-upaya organisasi maupun pemimpin untuk memperhatikan segala aspek yang menunjang lahirnya kinerja yang baik dengan memaksimalkan produktivitas karyawan, tim, dan akhirnya organisasi.

Kepemimpinan merupakan kemampuan mempengaruhi aktivitas orang lain melalui komunikasi, baik individual maupun kelompok, kearah pencapaian tujuan (Anoraga, 2004:182). Seorang pemimpin harus dapat mengerti dengan situasi dan kondisi organisasi yang ia pimpin selain itu Peningkatan kinerja karyawan tak lepas dari peran aktif pimpinan didalam memimpin karyawannya serta melakukan sistem manajemen yang baik.

Setiap pemimpin pada dasarnya memiliki perilaku yang berbeda dalam memimpin para karyawannya, perilaku para pemimpin itu disebut dengan gaya kepemimpinan. Gaya kepemimpinan merupakan suatu cara pemimpin untuk mempengaruhi anggotanya yang dinyatakan dalam bentuk pola tingkah laku atau kepribadian. Ada empat indikator gaya kepemimpinan (Griffin, 2004:83), yaitu: pemimpin pengarah (Leader Directiveness), pemimpin pendukung (Leader Supportiveness), pemimpin peranserta (Participative Leadership), kepemimpinan berorientasi prestasi (Achievement-Oriented Leadership)

Pemimpin juga harus dapat menciptakan suasana kerja yang nyaman dan tentram bagi karyawan agar karyawan dapat mengerjakan pekerjaannya dengan penuh semangat yang nantinya akan berdampak pada kinerja karyawan. Kemudian upaya lain untuk meningkatkan kinerja karyawan dapat dilihat dari cara atau gaya seorang pimpinan memimpin karyawannya yang mana gaya kepemimpinan seorang pemimpin yaitu kepemimpinan otokratis, demokratis, dan kebebasan (LaisserFaire) (Anoraga, 2004:186).

Selain dari gaya kepemimpinan yang diterapkan oleh seorang pimpinan organisasi, selanjutnya faktor lain yang dapat mempengaruhi kinerja karyawan adalah motivasi. Motivasi merupakan salah satu unsur pokok dalam perilaku seseorang. Dimana seseorang akan dapat melakukan kegiatan apabila ada keinginan yang timbul dari dalam diri orang tersebut (Thoha, 2011:203).

Perilaku manusia itu pada hakekatnya adalah berorientasi pada tujuan, dengan kata lain bahwa perilaku seseorang itu pada umumnya diransang oleh keinginan untuk mencapai beberapa tujuan (Thoha, 2011:206). Untuk itu perlu seorang pimpinan untuk mengetahui keinginan serta kebutuhan karyawannya yang mengundangnya untuk mau mengerjakan suatu aktivitas tertentu. 
Seorang pimpinan harus dapat mengetahui unsur-unsur motivasi yang ada pada diri karyawannya dan dapat memenuhi kebutuhan tersebut agar karyawan dapat termotivasi untuk mau bekerja yang nantinya akan dapat tercapainya tujuan organisasi. Dengan tercapainya tujuan organisasi berarti kinerja karyawan meningkat.

Motivasi seseorang akan ditentukan oleh stimulusnya. Stimulus yang dimaksud merupakan mesin penggerak motivasi seseorang sehingga menimbulkan pengaruh perilaku seseorang yang bersangkutan. Motivasi seseorang biasanya meliputi hal-hal sebagai berikut: Kinerja (Achievement), Penghargaan (Recognition), Tantangan (Challange), Tanggung Jawab (Responsibility), Pengembangan (Development), Keterlibatan (Involvement), dan Kesempatan (Opportunity) Sangir (dalam Siswanto, 2005:122)

\section{Pengertian Gaya Kepemimpinan}

Menurut Siswanto (2005:24) gaya kepemimpinan merupakan cara atau tipe yang ada pada diri seorang pimpinan didalam memanajemen para anggotanya (karyawan) untuk dapat menjalankan amanat yang diberikan untuk mencapai tujuan tertentu. Untuk melihat seorang manajer didalam mengembangkan kinerja karyawannya, maka dapat dilihat dari gaya seorang pemimpin tersebut didalam memimpin karyawannya.

House (dalam Robbins ,2010:156), mengidentifikasikan empat prilaku kepemimpinan yaitu pemimpin yang mengarahkan (Directive Leader) adalah pimpinan memberitahukan kepada bawahan apa yang diharapkan dari mereka, jadwal pekerjaan yang harus diselesaikan, serta memberikan bimbingan/arahan secara spesifik tentang cara-cara menyelesaikan tugas.

\section{Pengertian Motivasi}

Motivasi merupakan suatu bentuk keinginan yang timbul dalam diri seseorang untuk mencapai sesuatu yang ia inginkan. Menurut Berelson dan Steiner (dalam Siswanto,2005:119) mendefinisikan motivasi sebagai all those inner striving conditions variously described as wishes, needs, drivers, and the like.

Motivasi dapat diartikan sebagai keadaan kejiwaan dan sikap mental manusia yang memberikan energi, mendorong kegiatan (Moves), dan mengarah atau menyalurkan pilaku kearah mencapai kebutuhan yang memberi kepuasan atau mengurangi ketidakseimbangan.

\section{Pengertian Kinerja}

Istilah kinerja berasal dari kata job performance atau actual performance (prestasi kerja atau prestasi sesungguhnya dicapai oleh seseorang). Menurut Mondy (2008:132), kinerja merupakan proses berorientasi tujuan yang diarahkan untuk memastikan bahwa proses-proses keorganisasian ada pada tempatnya untuk memaksimalkan produktivitas para karyawan, tim, dan akhirnya organisasi.

\section{METODE PENELITIAN}

\section{Jenis Penelitian}

Jenis penelitian yang digunakan adalah deskriptif asosiatif. Siregar (2013:15) menyatakan bahwa penelitian deskriptif asosiatif adalah penelitian yang betujuan untuk mengetahui hubungan sebab-akibat antara dua variabel atau lebih.

\section{Tempat dan Waktu Penelitian}

Tempat penelitian ini dilakukan di Badan Pusat Statistik Kota Padang yang beralamatkan di jalan By Pass, Kecamatan Kuranji. Waktu pelaksanaan penelitian direncanakan pada Tanggal1 Juli sampai 30 Agustus Tahun 2013

\section{Populasi}

Menurut Arikunto (2006:23), populasi adalah keseluruhan objek 
penelitian. Dalam penelitian ini, maka yang dijadikan sebagai objek penelitian adalah karyawan Badan Pusat Statistik Kota Padang yang berjumlah 30 karyawan.

Menurut Arikunto (2006:24) sampel adalah bagian dari populasi yang akan dijadikan wakil daripada objek penelitian tersebut. Jadi, metode pengambilan sampel yang dilakukan peneliti dalam penelitian ini adalah metode sensus. Menurut Sugiyono (2012:85) metode sensus adalah teknik penentuan sampel apabila semua anggota populasi dijadikan sebagai sampel. Dalam penelitian ini di gunakan sistem penentuan sampelnya yaitu total sampling karena populasinya kurang dari 100 orang karyawan. Jadi, jumlah sampel adalah 30 orang karyawan Badan Pusat Statistik (BPS) Kota Padang .

\section{Jenis dan Sumber Data}

1. Data Primer merupakan data yang berhubungan dengan variabel gaya kepemimpinan (X1), motivasi kerja (X2), dan kinerja (Y) yang diperoleh melalui penyebaran angket yang disebarkan kepada 30 orang karyawan Badan Pusat Statistik Kota Padang.

2. Data sekunder merupakan data yang bersumber dari kepustakaan dan dokumentasi resmi serta catatan berupa data angka, dan laporan yang berkaitan dengan penelitian ini pada Badan Pusat Statistik (BPS) Kota Padang.

\section{Variabel Penelitian}

Dalam penelitian ini terdapat dua variabel penyebab dan satu variabel akibat adalah sebagai berikut :

a. Variabel penyebab (eksogenus) terdiri dari gaya kepemimpinan $\left(\mathrm{X}_{1}\right)$ dan motivasi kerja $\left(\mathrm{X}_{2}\right)$ sebagai variabel intervening.

b. Variabel akibat yaitu kinerja (endogenus) (Y).

\section{Teknik Analisis Data} Analisis Deskriptif
Menurut Bungin, (2005:181) analisis deskriptif merupakan penelitian kuantitatif yang bertujuan untuk mendeskripsikan keadaan gejala sosial yang tampak dan melihat hubungan kausalitas antara gejala-gejala tersebut.Setelah data terkumpul kemudian disajikan ke dalam tabel distribusifrekuensi untuk dilakukan analisis deskriftif.

Menghitung nilai TCR masingmasing kategori jawaban dari deskriptif variabel, maka dapat dihitung dengan menggunakan rumus sebagai berikut : $T C R=\frac{R s}{n} \times 100 \%$

Dimana :

TCR =Tingkat Capaian Responden

Rs =Rata-rata skor jawaban responden

$\mathrm{n}$ =Jawaban responden

Analisis ini digunakanuntuk melihat gambaran secara umum tentang variabel yang ditelitidengan analisis persentase. Untuk mencari persentase jawaban angket dari responden digunakan rumus :

$$
P=\frac{F}{n} \times 100 \%
$$

Dimana : $\quad \mathrm{P}=$ Persentase yang dicari

$$
\mathrm{f}=\text { Frekuensi }
$$$$
\mathrm{n}=\text { Jumlah responden }
$$

Pengkategorian nilai pencapaian resonden digunakan klasifikasi (Bungin, 2005:172) :

90\% - 100\% Sangat Baik

$80 \%-89 \% \quad$ Baik

$65 \%-79 \% \quad$ Cukup

$55 \%-64 \%$ Buruk

$0 \%-54 \% \quad$ Sangat Buruk

Untuk mendapatkan rata-rata skor masing-masing indikator dalam pernyataan-pernyataan yang terdapat dalam kuisioner dipakai rumus berikut :

Rata - rata skor

$=\frac{(5 . S T)+(4 . S)+(3 . N)+(2 . T S)+(1 . S T S)}{S T+S+N+T+S T S}$

Dimana :

ST = Sangat setuju

$\mathrm{S} \quad=$ Setuju

$\mathrm{N} \quad=$ Netral

TS = Tidak setuju 
STS = Sangat tidak setuju

Uji Asumsi Klasik

1. Uji Normalitas

2. Uji Homogenitas

\section{Analisis Jalur}

Menurut Idris (2010:181) analisis jalur digunakan untuk menganalisis hubungan antar variabel dari model yang dibuat peneliti berdasarkan teori-teori yang ada, dan bukan suatu dugaan cobacoba. Untuk menerangkan pengaruh langsung dan pengaruh tidak langsung dapat diterangkan pada diagram jalur sebagai berikut :

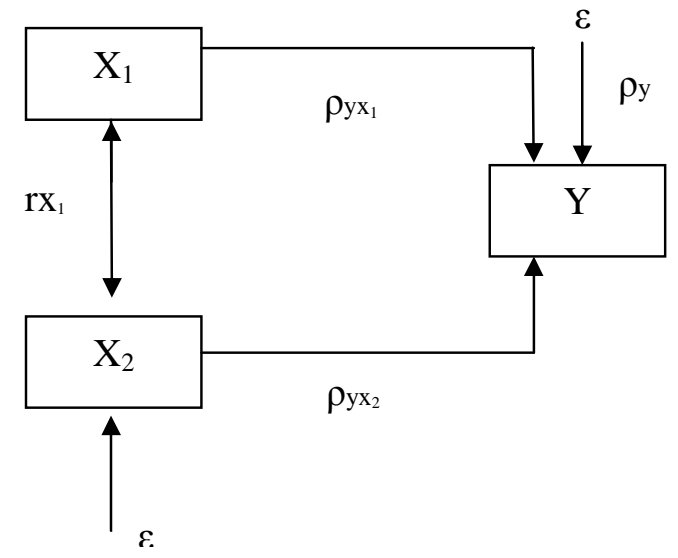

\section{Gambar 1. Struktur Pengaruh Variabel Bebas Terhadap Variabel Terikat}

Hasil besaran diagram jalur diatas menunjukkan besarnya pengaruh masingmasing variabel bebas terhadap variabel terikat yang disebut dengan koefisien jalur. Selanjutnya diagram diatas dapat dipecah menjadi dua substurktur sehungga struktur analisis jalurnya dapat digambarkan sebagai berikut :

1) Substruktur 1

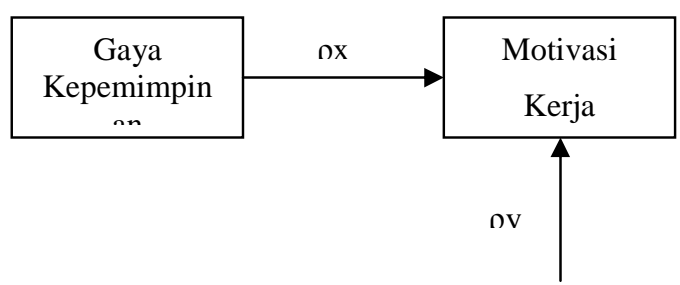

\section{Gambar2. Struktur Pengaruh Variabel Gaya Kepemimpinan Terhadap Motivasi Kerja}

Berdasarkan substruktur 1 di atas dapat dibuat persamaan strukturnya sebagai berikut

2) Substruktur 2

$$
\mathrm{X}_{2}=\rho \mathrm{x}_{2} \mathrm{x}_{1} \cdot \mathrm{x}_{1}+\mathrm{e}
$$

$$
\mathrm{Y}=\rho \mathrm{yx}_{1} \cdot \mathrm{x}_{1}+\rho \mathrm{yx}_{2} \cdot \mathrm{x}_{2}+\mathrm{e}
$$

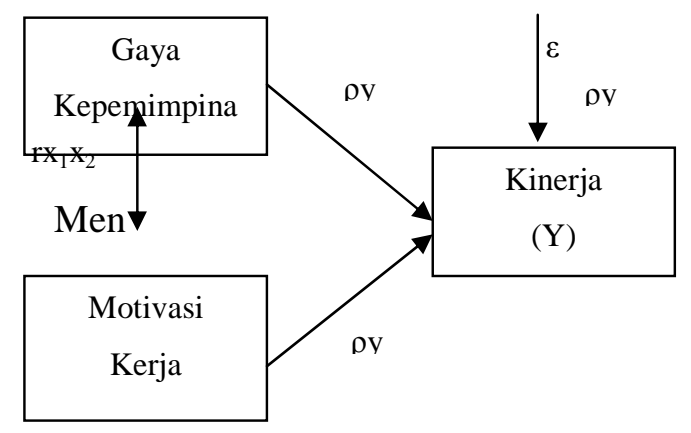

\section{Gambar 3. Struktur Pengaruh Variabel Gaya Kepemimpinan dan Motivasi Terhadap Kinerja}

Menurut Abdurrahman, dkk (2001:248) untuk menentukan koefisien jalur adalah sebagai berikut :

1. Koefisien Regresi, dengan rumus :

$$
\begin{gathered}
\text { byxi }= \\
\sum_{h=1}^{n} \text { Xih Yh }+\ldots \text { Cik } \sum_{\mathrm{h}-1}^{\mathrm{n}} \mathrm{Xkh} \mathrm{Yh}
\end{gathered}
$$

2. Koefisien Jalur, dengan rumus :

Keterangan :

$$
\text { Pyxi }=\sqrt[b y x i]{\sum_{\frac{h-1}{\sum_{h-1}^{n} Y}}^{n} x^{2} i h}
$$


pyxi $=$ Koefisien jalur dari variabel $\mathrm{Xi}$ terhadap Y

byxi $=$ Koefisien regresi dari variabel $\mathrm{Xi}$ terhadap Y

Menurut Abdurrahman, dkk (2001:248) untuk menguji signifikasi pengaruh X1 terhadap Y digunakan rumus sebagai berikut :

$$
t i=\frac{P y x i}{\sqrt{\frac{\left(1-R^{2} Y x i \ldots . . Y X k\right) \cdot(R i i)}{n-k-1}}}
$$

Keterangan :

pyxi $=$ Koefisien jalur dari variabel Xi terhadap Y

$\mathrm{R}^{2}$ Yxi....YXK = Koefisien yang menyatakan determinasi total dari semua variabel terhadap variabel eksogen

Sedangkan pengaruh variabel lain dapat ditentukan dengan rumus :

Dimana :

$$
\text { Pye }=\sqrt{1-R^{2} Y x 1 \times 2}
$$

$R^{2} Y x i \ldots . x 1=$ merupakan koefisien yang menyatakan determinasi total dari semua variabel penyebab terhadap variabel akibat

Menentukan pengaruh dari satu variabel eksogen $(\mathrm{X})$ ke variabel endogen (Y), baik secara langsung maupun tidak secara langsung.

Untuk X1:

Menentukan pengaruh langsung :

$$
\mathrm{Y} \longleftarrow \mathrm{X}_{1} \longrightarrow \mathrm{Y}: \rho \mathrm{yx}_{1} \rho \mathrm{yx}_{1}
$$

Menentukan pengaruh tidak langsung :

$$
Y \leftarrow X_{1} \Omega X_{2}: \rho y_{1} \mathrm{rx}_{1} \mathrm{X}_{2} \rho \mathrm{yx}_{2}
$$

Untuk $\mathrm{X}_{2}$ :

Menentukan pengaruh langsung :

$$
\mathrm{Y} \longleftarrow \mathrm{X}_{2} \longrightarrow \mathrm{Y}: \mathrm{\rho yx}_{2} \rho \mathrm{yx}_{2}
$$

Menentukan pengaruh tidak langsung :

$$
\mathrm{Y} \longleftarrow \mathrm{X}_{2} \Omega \mathrm{X}_{1} \longrightarrow \mathrm{Y}: \rho \mathrm{yx}_{2} \mathrm{rx}_{2} \mathrm{x}_{1} \rho \mathrm{yx}_{1}
$$

\section{Uji Hipotesis}

1. Uji t (Uji Signifikansi Parsial)

Untuk menguji hipotesis 1 maka digunakan uji t, yaitu untuk melihat pengaruh variabel eksogenus terhadap variabel endogen dengan rumus sebagai berikut :

$$
\text { to }=\frac{b i}{S b i}
$$

Di mana $:$ to $=$ Koefisien nilai tes

$$
\begin{aligned}
& \text { bi }=\text { Koefisien regresi } \\
& \text { Sbi = Standar kesalahan } \\
& \text { koefisien regresi }
\end{aligned}
$$

Hipotesis yang di uji dengan t kriterianya adalah sebagai berikut :

Jika thitung $\geq$ tabel pada taraf signifikansi $(\alpha=0,05)$ maka Ho di tolak sedangkan jika thitung $<$ tabel pada taraf signifikansi $(\alpha=0,05)$ maka Ho di terima.

2. Uji F (Uji Signifikansi Simultan)

Menurut Abdurrahman, dkk (2001:249) dalam penelitian ini, uji F digunakan untuk mengetahui tingkat signifikasi pengaruh variabel-variabel independen secara simultan terhadap variabel dependen. Untuk mengetahui besarnya pengaruh antar variabel secara keseluruhan maka digunakan rumus sebagai berikut :

$$
F=\frac{(n-k-1) \sum_{i-1}^{k} \text { Pyxi.Ryxi }}{K\left(1-\sum_{i-1}^{K} \text { Pyxi.Ryxi }\right)}
$$

Setelah diperoleh nilai Fhitung, selanjutnya dibandingkan dengan nilai Ftabel jika Fhitung> Ftabelpada taraf signifikansi $(\alpha=0,05)$, maka Ho ditolak. Selanjutnya jika Fhitung < Ftabelpada taraf signifikansi $(\alpha=0,05)$ maka Ho diterima.

\section{PEMBAHASAN}

\section{Pengaruh Gaya Kepemimpinan Terhadap Motivasi Kerja Karyawan}

1. Hasil analisis menunjukkan bahwa $\mathrm{F}$ hitung 5.602 dengan tingkat level Sig. $0.025<0.05$. Hal ini dapat diartikan terdapat pengaruh yang positif dan signifikan Gaya Kepemimpinan terhadap Motivasi Kerja karyawan Badan Pusat Statistik (BPS) Kota Padang. Besaran koefisien adalah 0.408, angka koefisien jalur ini menunjukkan angka yang positif, artinya semakin ditingkatkan skor Gaya Kepemimpinan maka skor Motivasi Kerja akan meningkat pula. 


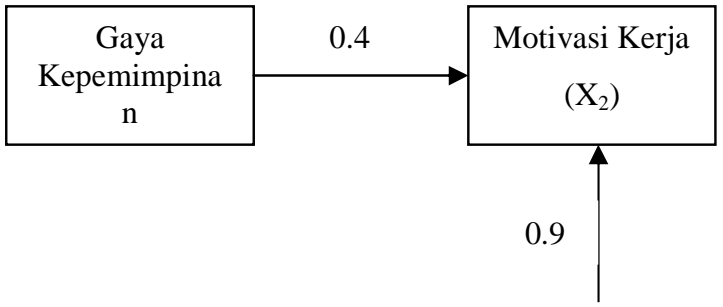

\section{Gambar 4.Sub Struktur I}

2. Pengaruh variabel lain terhadap variabel terikat

$$
\begin{aligned}
& \text { Pye }=\sqrt{1-R^{2} Y x 1 \times 2} \\
& \text { Pye }=\sqrt{1-0.167} \\
& \text { Pye }=\sqrt{0.833}=0.9126
\end{aligned}
$$

Koefisien tersebut memberikan makna bahwa pengaruh variabel lain terhadap variabel intervening adalah sebesar $0.9126=91.26 \%$.

Pengaruh Gaya Kepemimpinan Terhadap Kinerja Karyawan Badan Pusat Statistik (BPS) Kota Padang Tabel 1. Koefisien Jalur Variabel Gaya Kepemimpinan (X1) Terhadap Variabel Akibat Kinerja Karyawan (Y)

\begin{tabular}{llccc}
\hline No & $\begin{array}{l}\text { Variabel yang } \\
\text { Berpengaruh }\end{array}$ & $\begin{array}{l}\text { Koefisien } \\
\text { Jalur }\end{array}$ & thitung & Sig. \\
\hline 1 & $\begin{array}{l}\text { Gaya Kepemimpinan } \\
\left(\mathrm{X}_{1}\right)\end{array}$ & 0.364 & 2.158 & 0.040 \\
& \multicolumn{3}{c}{ Variabel Akibat: Kinerja Karyawan (Y) } &
\end{tabular}

Sumber: Olahan Data Primer 2013

Hasil analisis menunjukkan bahwa $\mathrm{t}$ hitung 2.158 dengan tingkat level Sig. $0.040<0.05$. Hal ini dapat diartikan terdapat pengaruh positif dan signifikan antara Gaya Kapemimpinan terhadap Kinerja Karyawan Badan Pusat Statistik (BPS) Kota Padang. Besaran koefisien 0.364 hal ini menunjukkan bahwa semakin baik Gaya Kepemimpinan maka akan semakin meningkat pula Kinerja karyawan.
Pengaruh Motivasi Kerja Terhadap Kinerja Karyawan Badan Pusat Statistik (BPS) Kota Padang

Tabel 2.Koefisien Jalur Variabel Motivasi Kerja $\left(\mathbf{X}_{2}\right)$ Terhadap Variabel Akibat Kinerja Karyawan (Y)

\begin{tabular}{clccc}
\hline No & $\begin{array}{l}\text { Variabel yang } \\
\text { Berpengaruh }\end{array}$ & $\begin{array}{c}\text { Koefisien } \\
\text { Jalur }\end{array}$ & thitung & Sig. \\
\hline 1 & Motivasi Kerja $\left(\mathrm{X}_{1}\right)$ & 0.351 & 2.080 & 0.047
\end{tabular}

Variabel Akibat: Kinerja Karyawan (Y)

Sumber: Olahan Data Prime

Hasil analisis menunjukkan bahwa t hitung 2.080 dengan tingkat level Sig. $0.047<0.05$. Hal ini dapat diartikan terdapat pengaruh signifikan antara Motivasi Kerja terhadap Kinerja Karyawan Badan Pusat Statistik (BPS) Kota Padang. Besaran koefisien 0.351 hal ini menunjukkan bahwa semakin baik Motivasi Kerja maka akan semakin meningkat pula Kinerja karyawan.

Pengaruh Gaya Kepemimpinan dan Motivasi Kerja Terhadap Kinerja Karyawan Badan Pusat Statistik (BPS) Kota Padang

Untuk menganalisis pengaruh variabel penyebab Gaya Kepemimpinan $\left(\mathrm{X}_{1}\right)$ dan Motivasi Kerja $\left(\mathrm{X}_{2}\right)$ terhadap variabel akibat Kinerja (Y), baik secara bersama-sama maupun secara parsial. Hasil analisis disajikan dalam Tabel 3 dan Tabel 4. secara bersama-sama dilakukan melalui ANOVA yang disajikan dalam

\begin{tabular}{|c|c|c|c|c|c|c|}
\hline \multicolumn{2}{|c|}{ Model } & $\begin{array}{l}\text { Sum of } \\
\text { Squares }\end{array}$ & Df & $\begin{array}{l}\text { Mean } \\
\text { Square }\end{array}$ & $\mathrm{F}$ & Sig. \\
\hline \multirow[t]{3}{*}{1} & $\begin{array}{l}\text { Regre } \\
\text { ssion }\end{array}$ & 85.204 & 2 & 42.602 & 7.820 & $.002^{\mathrm{a}}$ \\
\hline & $\begin{array}{l}\text { Residu } \\
\text { al }\end{array}$ & 147.096 & 27 & 5.448 & & \\
\hline & Total & 232.300 & 29 & & & \\
\hline
\end{tabular}
Tabel 3 berikut:

Tabel 3. AnOva

Berdasarkan data di atas, terlihat bahwa nilai $\mathrm{F}$ hitung sebesar 7.820 dengan tingkat level signifikansi sebesar 
$0.002<0.05$. Hal ini menunjukkan bahwa secara bersama-sama Gaya Kepemimpinan dan Motivasi Kerja memiliki pengaruh yang signifikan terhadap Kinerja Karyawan. Kemudian dilajutkan dengan uji secara parsial, uji ini berdasarkan analisis data yang disajikan dalam Tabel 4.12 berikut:

Tabel 4. Koefisien Sub Struktur II

\begin{tabular}{clccc}
\hline No & \multicolumn{1}{c}{$\begin{array}{c}\text { Variabel yang } \\
\text { Berpengaruh }\end{array}$} & $\begin{array}{c}\text { Koefisien } \\
\text { Jalur }\end{array}$ & thitung & Sig. \\
\hline 1 & $\begin{array}{l}\text { Gaya Kepemimpinan } \\
\left(\mathrm{X}_{1}\right)\end{array}$ & 0.364 & 2.158 & 0.040 \\
2 & Motivasi Kerja $\left(\mathrm{X}_{2}\right)$ & 0.351 & 2.080 & 0.047 \\
\multicolumn{5}{c}{ Kinerja $(\mathrm{Y})$} \\
\multicolumn{5}{l}{ Sumber: Olahan Data Primer 2013 }
\end{tabular}

Dari Tabel 4.dapat dilakukan uji secara sendiri-sendiri masing-masing variabel penyebab terhadap variabel akibat sebagai berikut:

1. Hasil analisis menunjukkan bahwa $\mathrm{t}$ hitung 2.158 dengan tingkat level Sig. $0.040<0.05$. Hal ini dapat diartikan terdapat pengaruh signifikan antara Gaya Kapemimpinan terhadap Kinerja Karyawan Badan Pusat Statistik (BPS) Kota Padang. Besaran koefisien 0.364 hal ini menunjukkan bahwa semakin baik Gaya Kepemimpinan maka akan semakin meningkat pula Kinerja karyawan.

0.408

2. Hasil analisis menunjukkan bahwa $t$ hitung 2.080 dengan tingkat level Sig. $0.047<0.05$. Hal ini dapat diartikan terdapat pengaruh signifikan antara Motivasi Kerja terhadap Kinerja Karyawan Badan Pusat Statistik (BPS) Kota Padang. Besaran koefisien 0.351 hal ini menunjukkan bahwa semakin baik Motivasi Kerja maka akan semakin meningkat pula Kinerja karyawan.

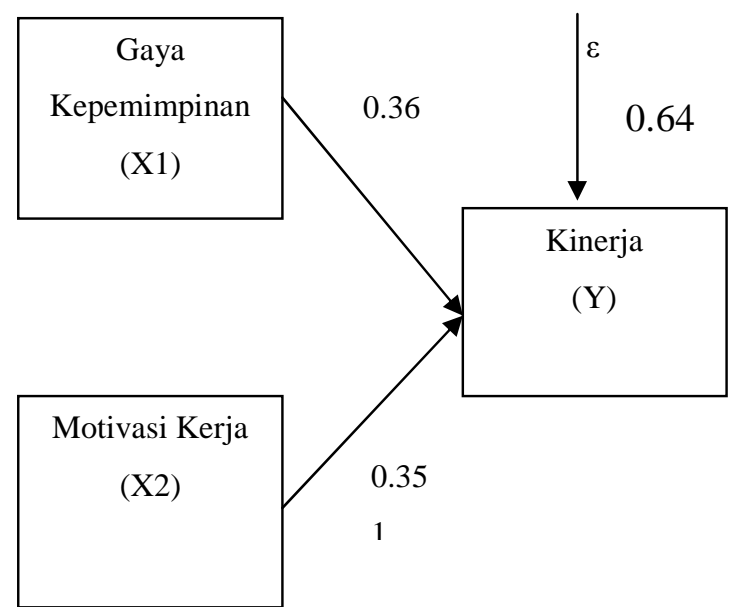

Gambar 5.Sub Struktur II

3. Pengaruh variabel lain terhadap variabel terikat

Pada tahap ini penulis melakukan perhitungan terhadap variabel lain yang tidak dimasukkan dalam model dengan menggunakan rumus yang dikemukakan oleh Abdurrahman, dkk (2001:248) adalah sebagai berikut:

$$
\begin{aligned}
& \text { Pye }=\sqrt{1-R^{2} Y x 1 \times 2} \\
& \text { Pye }=\sqrt{1-0.360} \\
& \text { Pye }=\sqrt{0.64}=0.8
\end{aligned}
$$

Koefisien tersebut memberikan makna bahwa pengaruh variable lain terhadap Kinerja Karyawan sebesar $0.64=$ $64 \%$

\section{PENUTUP}

\section{Kesimpulan}

Berdasarkan analisis dan pembahasan hasil pengujian hipotesis dapat disimpulkan beberapa poin di dalam penelitian ini, yaitu:

1. Terdapat pengaruh positif dan signifikan antara gaya kepemimpinan terhadap motivasi kerja karyawan pada Badan Pusat Statistik (BPS) Kota Padang dengan koefisien regresi 0.408 . Artinya peningkatan motivasi kerja karyawan dapat dilakukan dengan melakukan perbaikan terhadap gaya kepemimpinan pada Badan Pusat Statistik (BPS) Kota Padang. 
2. Terdapat pengaruh yang positif dan signifikan antara gaya kepemimpinan terhadap kinerja karyawan pada Badan Pusat Statistik (BPS) Kota Padang dengan koefisien regresi 0.364. Artinya peningkatan kinerja karyawan dapat dilakukan dengan melakukan perbaikan terhadap gaya kepemimpinan pada Badan Pusat Statistik (BPS) Kota Padang

3. Terdapat pengaruh yang positif dan signifikan antara motivasi kerja terhadap kinerja karyawan pada Badan Pusat Statistik (BPS) Kota Padang dengan koefisien regresi 0.351. Artinya peningkatan kinerja karyawan dapat dilakukan dengan melakukan perbaikan terhadap motivasi kerja karyawan pada Badan Pusat Statistik (BPS) Kota Padang.

4. Terdapat pengaruh yang positif dan signifikan antara variabel gaya kepemimpinan dan motivasi kerja terhadap kinerja karyawan pada Badan Pusat Statistik (BPS) Kota Padang. Diperoleh nilai $F_{\text {hitung }}$ sebesar 7.820 dengan nilai signifika sebesar 0.002 . Nilai sig < dari $\alpha$ yaitu $(0,002<$ $0,05)$ dengan demikian dapat diartikan bahwa variabel gaya kepemimpinan dan motivasi kerja secara bersama-sama berpengaruh signifikan terhadap kinerja karyawan.

Nilai $R$ square sebesar 0,3598 menunjukan bahwa besarnya pengaruh gaya kepemimpinan dan motivasi kerja terhadap kinerja karyawan adalah sebesar $35.98 \%$ dan sisanya $64.02 \%$ dipengaruh oleh variabel lain yang tidak termasuk kedalam model penelitian seperti kompensasi, iklim kerja, disiplin kerja,

\section{Keterbatasan Penelitian}

Penelitian yang telah selesai dilaksanakan ini masih memiliki beberapa kelemahan yang disebabkan karena adanya keterbatasan dalam penelitian ini yang meliputi yaitu;

1. Penelitian ini dibatasi oleh beberapa variabel saja dengan tujuan agar penelitian ini lebih fokus dan tidak mengambang. Hal ini dikarenakan peneliti hanya membahas tentang pengaruh gaya kepemimpinan dan motivasi kerja terhadap kinerja karyawan Badan Pusat Statistik (BPS) Kota Padang.

2. Masih terlalu minim dan sedikitnya jumlah sampel yang digunakan dalam penelitian ini membuat hasil yang diperoleh menjadi kurang sempurna.

\section{Saran}

Berdasarkan hasil yang ditemukan didalam penelitian ini, maka diajukan beberapa saran sebagai berikut:

1. Terdapat pengaruh positif dan signifikan antara gaya kepemimpinan terhadap motivasi kerja karyawan pada Badan Pusat Statistik (BPS) Kota Padang. Oleh karena itu, penulis menyarankan agar pimpinanBadan Pusat Statistik (BPS) Kota Padang lebih meningkatkan dan menerapkan gaya kepemimpinannya dengan lebih baik lagi agar motivasi yang dimiliki oleh karyawan Badan Pusat Statistik (BPS) Kota Padang lebih meningkat pula.

2. Terdapat pengaruh yang positif dan signifikan antara gaya kepemimpinan terhadap kinerja karyawan pada Badan Pusat Statistik (BPS) Kota Padang.Penulis menyarankan agar pimpinanBadan Pusat Statistik (BPS) Kota Padang lebih meningkatkan dan menerapkan gaya kepemimpinannya sebaik mungkin agar kinerja organisasi lebih baik dan meningkat.

3. Terdapat pengaruh yang positif dan signifikan antara motivasi kerja terhadap kinerja karyawan pada Badan Pusat Statistik (BPS) Kota Padang. Penulis menyarankan agar pimpinanBadan Pusat Statistik (BPS) Kota Padang selalu memberikan motivasi kepada karyawan agar kinerja organisasi dapat lebih meningkat pula.

4. Terdapat pengaruh yang positif dan signifikan antara variabel gaya kepemimpinan dan motivasi kerja 
terhadap kinerja karyawan pada Badan Pusat Statistik (BPS) Kota Padang. Penulis menyarankan agar pimpinanBadan Pusat Statistik (BPS) Kota Padang lebih meningkatkan dan menerapkan gaya kepemimpinannya serta memberikan motivasi kepada Karyawan

\section{DAFTAR PUSTAKA}

10.22202/economica.2014.v2.i2.226

Abdurahman, dkk. 2011. Dasar-Dasar Metode Statistika untuk Penelitian. Jawa Barat: CV. Pustaka Setia.

Akhirmen. 2005. Statistika 1. Padang: Fekon UNP. 2010. Statistik 1 (Teori dan Aplikasi). Padang: FE UNP.

Ali, Muhammad. 2010. Guru dalam Proses Belajar Mengajar. Bandung: Sinar Baru Algesindo.

Arikunto, Suharsimi. 2002. Prosedur Penelitian Suatu Pendekatan Praktik. Bandung: PT. Rineka Cipta. . 2010. Prosedur Penelitian Suatu Pendekatan Praktik. Bandung: PT. Rineka Cipta.

Djamarah, Syaiful Bahri. 2002. Psikologi Belajar. Jakarta: PT. Rineka Cipta.

Depdiknas. 2008. Pengawaswonomerto2012.blospot.com /10/kriteria-ketuntasan-minimal. Html.

Dimyati \& Mudjiono.2002. Belajar dan Pembelajaran. Jakarta:Rineka Cipta.

Dwinda, Lovelly Dahen. 2006. Pengaruh Motivasi Belajar dan Persepsi Siswa Tentang Gaya Mengajar Guru Terhadap Hasil Belajar Akuntansi Siswa Di SMKN 3 Padang. Skripsi Tidak Diterbitkan. Padang: UNP.

Febriyanawati, Riska. 2011. Pengaruh Persepsi Siswa tentang Mata Pelajaran Ekonomi dan Gaya Mengajar Guru Terhadap Hasil Belajar Siswa Kelas XI Jurusan Ilmu Sosial SMA Negeri Kota Kediri. Perpustakaan Digital. Jurnal: UNM.
Ghozali, Imam. 2012. Aplikasi Analisis Multivariate dengan Program IBM SPSS 20. Semarang: Undip. 